Her account of labour could usefully be read by professionals as giving further insight into how mothers feel. And nowadays professionals welcome intelligent and informed co-operation from their patients, the days of Olympian isolation being past.

But is this sort of book the most suitable kind for an expectant mother to read? It may help her in a number of ways, may give her many useful and encouraging ideas, may even in some cases suggest questions that she should ask herself and others that will lead her to greater freedom to think and act as herself. But on the other hand might she gain the impression that the experience of childbirth should be the same for every woman, or that Mrs. Kitzinger's is the only way in which a labour should be conducted? This would lead to serious misunderstandings unless she could discuss things easily with her doctor or midwife in an atmophere of mutual respect. This is often possible and where it is not there may be a little blame on both sides.

Shila Ransom.

\section{ECONOMICS OF PUBLIC HEALTH}

Economics of Public Health. Measuring the Economic Impact of Diseases. By Burton A. Weisbrod. (Pp. 127+xv. 40s.) Philadelphia: University of Pennsylvania Press.

London: Oxford University Press. 1961.

Health services in a modern society are expensive and there is no likelihood of the total cost of medical care falling in the future as was confidently assumed when the National Health Service was created. Nevertheless economic benefits undoubtedly follow from some advances in medicine and public health, such as the eradication of malaria from a population or the conquest of tuberculosis. It would clearly be valuable to have some estimate of the economic losses caused by particular diseases so that the economic consequences of their eradication could be predicted. This could enable expenditure of public funds on health projects to be carried out more rationally.

In his book Dr. Weisbrod, an economist, attempts to show how the cost of ill-health can be estimated. $\mathrm{He}$ first builds an analytic framework for estimating the economic loss which is caused by premature death and disability of an individual at various ages, and for estimating the cost of curative health services. He then uses his estimates to quantify in monetary terms the economic losses in one year due to three particular diseases-cancer, tuberculosis, and poliomyelitis. $\mathrm{He}$ considers that even with the limited data available some of the most important losses due to a disease can be measured, and that the measurements can be useful in giving an order of priority to health projects according to anticipated economic benefits.

Dr. Weisbrod correctly starts from the assumption that the resources of a nation-human, material, and financial-are limited, and that attempts should be made to use these resources in the field of public health to achieve maximum benefits. Furthermore, if it can be clearly demonstrated that increasing expenditure of public funds in a particular area will increase the nation's productive resources, then it becomes more likely that the extra funds will be forthcoming. This is particularly true of a clear-cut public health operation such as clearing malarial swamps or installing a public sewage system, but it is also useful to have measurements of the economic impact of the major diseases of modern society such as cancer and coronary thrombosis. Dr. Weisbrod's book is a first step in the direction of cost-benefit analysis in health expenditure, an area of economics which has so far received hardly any attention.

JoHn SEALE.

\section{FIRST-YEAR LANDMARKS}

An Introduction to Developmental Assessment in the First Year. By R. S. Illingworth. Preface by Mary D. Sheridan. Little Club Clinics in Developmental Medicine 3. (Pp. 40; illustrated. 10s.) London: National Spastics Society (Medical Education and Information Unit) in association with William Heinemann Medical Books. 1962.

This slim volume is extremely well done. Within its 40 pages are set out with admirable clarity the developmental stages of the child's first year, under the headings of ventral, prone, and sitting postures; walking; manipulation ; eyes and ears ; feeding and dressing; and speech. Under each of these headings is given the stage reached at the age of $0,4,6$, and 8 weeks, and thereafter at four-week intervals. This is probably a more useful form for reference than the usual one of listing the attainments expected of a child aged so-many weeks. About half the book is made up of illustrations, and this allows the text to be brief and clearly printed in large type, which should make it easy to use as an aide mémoire in the welfare clinic and consulting-room.

Professor Illingworth has spent many years in applying in day-to-day clinical practice the methods of developmental diagnosis laid down by Gesell. In so doing he has been able to simplify their statement and to increase their usefulness. Here we have the distillate of his experience in an easily assimilable form and minus the prolixity of Gesell, which was perhaps a real barrier to the earlier acceptance of Gesell's work in this country. In any future edition one would like to see the assessment of the prematurely born child given more attention, as this is a frequent practical problem in child adoption. The subject is here dismissed in two lines which include a statement that some would question : "If a child is born 3 months prematurely, he should not be expected to smile till 3 months plus 4 weeks."

This is one of a series entitled "Little Club Clinics in Developmental Medicine" published by the National Spastics Society, which must be congratulated on adding medical publications of this quality (and at a reasonable price) to its many activities.

Douglas Gairdner.

\section{PNEUMOENCEPHALOGRAPHIC ATLAS}

An Atlas of Detailed Normal Pneumoencephalographic Anatomy. By Giovanni di Chiro, M.D. (Pp. 328+xii ; illustrated. £7 12s.) Springfield, Ill.: Charles C. Thomas. Oxford: Blackwell Scientific Publications. 1961.

Now that cerebral pneumoencephalography is being practised more and more widely there is need for a standard atlas not only of the ventricular system but also of all the extraventricular cerebrospinal fluid spaces within the head. In the past there has been nothing comprehensive available. Di Chiro has done a great service both to anatomy and radiology by bringing out this excellent atlas. Many of the subarachnoid pathways are difficult to depict by ordinary anatomical dissection, and no better way has yet been devised of demonstrating them than as radiographic shadows in life.

The author has made extensive use of various tomographic techniques which have served to enhance the 